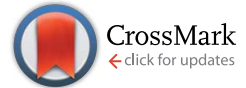

Cite this: Chem. Sci., 2017, 8, 1251

\title{
Micro-flow photosynthesis of new dienophiles for inverse-electron-demand Diels-Alder reactions. Potential applications for pretargeted in vivo PET imaging $\dagger$
}

\author{
Emilie M. F. Billaud, ${ }^{a}$ Elnaz Shahbazali, ${ }^{b}$ Muneer Ahamed, ${ }^{a}$ Frederik Cleeren, ${ }^{a}$ \\ Timothy Noël, ${ }^{\mathrm{b}}$ Michel Koole, ${ }^{\mathrm{c}}$ Alfons Verbruggen, ${ }^{a}$ Volker Hessel ${ }^{\mathrm{b}}$ \\ and Guy Bormans*a
}

Pretargeted PET imaging has emerged as an effective two-step in vivo approach that combines the superior affinity and selectivity of antibodies with the rapid pharmacokinetics and favorable dosimetry of smaller molecules radiolabeled with short-lived radionuclides. This approach can be based on the bioorthogonal inverse-electron-demand Diels-Alder (IEDDA) reaction between tetrazines and trans-cyclooctene (TCO) derivatives. We aimed to develop new $\left[{ }^{18} \mathrm{~F}\right] \mathrm{TCO}$-dienophiles with high reactivity for IEDDA reactions, and favorable in vivo stability and pharmacokinetics. New dienophiles were synthesized using an innovative micro-flow photochemistry process, and their reaction kinetics with a tetrazine were determined. In vivo stability and biodistribution of the most promising ${ }^{18} \mathrm{~F}$-radiolabeled-TCO-derivative $\left(\left[{ }^{18} \mathrm{~F}\right] 3\right)$ was investigated, and its potential for in vivo pretargeted PET imaging was assessed in tumor-bearing mice. We demonstrated that $\left[{ }^{18} \mathrm{~F}\right] 3$ is a suitable dienophile for IEDDA reactions and for pretargeting applications.

Received 4th July 2016

Accepted 6th October 2016

DOI: $10.1039 / \mathrm{c} 6 \mathrm{sc} 02933 \mathrm{~g}$

www.rsc.org/chemicalscience

maximum), and short $\beta^{+}$trajectory in tissues $(<2.3 \mathrm{~mm})$. Its half-life is long enough to allow multistep syntheses but is short enough to avoid extended irradiation of patients. Moreover, it can be produced in large quantities ( $>400 \mathrm{GBq}$ per batch) with a cyclotron. ${ }^{4}$

Combination of antibodies with fluorine-18 is challenging, due to the incompatibility between the long plasma half-life of the antibody and the short physical half-life of the radionuclide. Pretargeting addresses this issue in two steps. ${ }^{5}$ First, a nonradiolabeled antibody modified with a tag is administered. Few days later, when the antibody has reached a maximum uptake in the tumor and a sufficient clearance from non-target tissues, a relatively small radiolabeled molecule is injected. The latter has the property to selectively bind to the antibody via the tag, while the non-bound radiotracer is rapidly cleared. Then, high contrast images can be acquired few hours after the injection of the radiolabeled molecule. The overall radiation dose for patients is thus reduced, compared to the use of an antibody directly labeled with ${ }^{89} \mathrm{Zr}$ for instance.

Pretargeting approaches can be based on an inverse-elec-

${ }^{a}$ Laboratory of Radiopharmacy, Department of Pharmaceutical and Pharmacological Sciences, KU Leuven, Campus Gasthuisberg, O\&N2, Herestraat 49, Box 821, 3000 Leuven, Belgium. E-mail: guy.bormans@kuleuven.be

${ }^{b}$ Micro Flow Chemistry \& Process Technology, Chemical Engineering and Chemistry Department, TU Eindhoven, P. O. Box 513, 5600 MB Eindhoven, The Netherlands

${ }^{c}$ Nuclear Medicine and Molecular Imaging, Department of Imaging and Pathology, University Hospital and KU Leuven, Herestraat 49, Box 7003, 3000 Leuven, Belgium $\dagger$ Electronic supplementary information (ESI) available. See DOI: $10.1039 / \mathrm{c} 6 s c 02933 \mathrm{~g}$ tron-demand Diels-Alder (IEDDA) click reaction between 1,2,4,5-tetrazines and trans-cyclooctene (TCO) derivatives. ${ }^{6}$ Indeed, this fast, selective, high-yield, biocompatible, and bioorthogonal reaction has already proven to be suitable for this kind of applications, both in vitro and in vivo, ${ }^{7}$ even using ${ }^{18} \mathrm{~F}$-labeled tetrazines. ${ }^{8}$ However, to the best of our knowledge, no in vivo pretargeting PET imaging results have been reported on using 


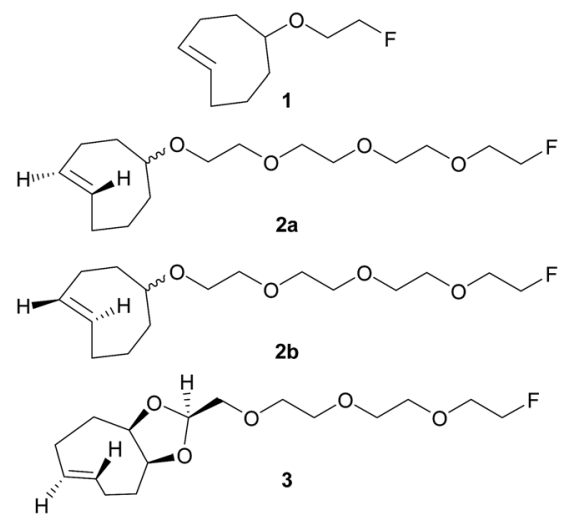

Fig. 1 Chemical structures of previously reported TCO derivative $1^{9}$ and newly developed dienophiles $2 \mathrm{a}, 2 \mathrm{~b}$, and 3 .

a ${ }^{18}$ F-labeled small TCO compound, although this approach may have specific advantages with regard to pharmacokinetics and stability. Some radiolabeling procedures were developed for TCO $\left[{ }^{18} \mathbf{F}\right] \mathbf{1}$ (Fig. 1) ${ }^{\mathbf{9}}$ but it was applied as a prosthetic group for subsequent ${ }^{18} \mathrm{~F}$-labeling of biologically-active molecules. ${ }^{10}$

Wyffels et al. explored biodistribution of $\left[{ }^{18} \mathbf{F}\right] \mathbf{1}$ in healthy mice, from 5 to 240 min p.i. ${ }^{9 b}$ Results demonstrated renal and hepatobiliary clearance of radioactivity, slow blood clearance, as well as increasing bone uptake values (from $60 \mathrm{~min}$ p.i.). The bone uptake is due to defluorination, as $\left[{ }^{18} \mathrm{~F}\right] \mathrm{F}^{-}$is known to have a high affinity for bone, and is an indication of tracer instability. Therefore, we aimed to develop new TCO derivatives, with improved in vivo stability, favorable pharmacokinetics, and high reactivity for IEDDA reactions.

We designed compounds $\mathbf{2 a}, \mathbf{2 b}$ and $\mathbf{3}$ derivatised with polyethylene glycol (PEG) chains (Fig. 1) with the aim to increase their hydrophilicity and their stability towards enzymatic degradation. ${ }^{7 l 11}$ We developed a conformationally-strained dioxolanefused trans-cyclooctene (3), encouraged by the results reported by Darko et al. ${ }^{12}$ Indeed, it was demonstrated that this strained trans-cyclooctenes react faster with 3,6-diphenyl-s-tetrazine than non strained analogs, and display excellent chemical stability in aqueous solutions and plasma. Moreover, dioxolane-fused trans-cyclooctenes can be prepared easily through diastereoselective synthesis.

Herein we report (i) the syntheses of new TCO derivatives, via a trans-for-cis photoisomerization step using an innovative micro-flow process; (ii) reaction kinetics of these new dienophiles with a tetrazine, as well as their stability in aqueous solution; (iii) ${ }^{18} \mathrm{~F}$-radiolabeling of the most promising TCO derivative 3 ; (iv) in vitro stability of $\left[{ }^{\mathbf{1 8}} \mathbf{F}\right] \mathbf{3}$ and in vivo biodistribution studies after injection of $\left[{ }^{18} \mathbf{F}\right] 3$; (v) proof of principle in vitro and in vivo pretargeting experiments using $\left[{ }^{\mathbf{1 8}} \mathbf{F}\right] \mathbf{3}$.

\section{Results and discussion}

\section{Syntheses}

New dienophiles 2a, 2b and $\mathbf{3}$ were prepared as shown in Scheme 1. First, the corresponding cis-derivatives 9 and 18 were synthesized, in 6 and 7 steps respectively.
PEG synthon 4 was obtained in two steps starting from tetraethylene glycol: protection of one hydroxyl group using triisopropylsilyl (TIPS) chloride followed by mesylation of the other hydroxyl group. Then, synthon 4 was used for nucleophilic substitution with cis-cyclooctenol to yield derivative $\mathbf{5}$. The choice of TIPS as the hydroxyl protecting group was important to obtain a good yield. After deprotection using tetrabutylammonium fluoride (TBAF), the hydroxyl group of compound 6 was replaced by fluorine (9) via a sulfonate intermediate.

For the synthesis of 18, PEG synthon 13 was first prepared in two steps starting from tetraethylene glycol: after protection of one hydroxyl group using benzoyl chloride $(\mathrm{BzCl})$, the other hydroxyl was oxidized to an aldehyde in the presence of Dess-Martin periodinane reagent. In parallel, oxidation of 1,5-cyclooctadiene into diol 12 was carried out using cetyltrimethylammonium permanganate. Then, PEG synthon 13 and diol 12 were involved in an acetalization, leading to dioxolane 14. The stereochemistry of $\mathbf{1 4}$ was determined according to Darko et al. ${ }^{12}$ After deprotection using LiOH, the hydroxyl group of compound $\mathbf{1 5}$ was replaced by fluorine (18) via a sulfonate intermediate.

Trans-for-cis isomerization of hydroxy-derivatives 6, 15, sulfonate precursors for radiofluorination 7, 8, 16, 17, and fluoro-derivatives $\mathbf{9}, \mathbf{1 8}$ was performed using an innovative microflow photochemistry process. Basic design of the setup was based on the work of Royzen et al. ${ }^{13}$ This group devised an apparatus where the reaction mixture, containing a cis-cyclooctene derivative and methyl benzoate (a singlet sensitizer), is photoirradiated at $254 \mathrm{~nm}$, and continuously circulated through a bed of $\mathrm{AgNO}_{3}$-impregnated silica gel. The transcyclooctene derivative forms a complex with $\mathrm{Ag}^{+}$and is selectively retained on the bed, while the corresponding cis-cyclooctene binds weakly to $\mathrm{Ag}^{+}$and elutes back to the reaction flask, where it is photoirradiated again. For trans-for-cis isomerization of our compounds, we used a micro-flow setup, since the short characteristic inner diameter of the microreactor allows a high overall absorption even at larger concentration which increases the gross conversion rate largely and reduces the reaction time from hours to minutes for typical photo-flow processes. ${ }^{\mathbf{1 4}}$ In addition, process scale-up is facilitated by the numbering-up of several flow microcapillaries with almost identical performance. ${ }^{15}$ Two microreactors coiled around the UV lamp were used in parallel, and flow was adjusted to result in 2 to $3 \mathrm{~min}$ irradiation time (Scheme 2 and ESI $\dagger$ ). Although Royzen et al. used 8 lamps of $35 \mathrm{~W}$ (light intensity: $12800 \mu \mathrm{W} \mathrm{cm}{ }^{-2}$ ), ${ }^{13}$ a single UV lamp of $10 \mathrm{~W}$ (light intensity: $21-24 \mu \mathrm{W} \mathrm{cm} \mathrm{cm}^{-2}$ ) provided sufficient power for the isomerization reaction in our micro-flow setup. In-flow separation process based on $\mathrm{Ag}^{+}$ complexation was also optimized, by using several packed beds made of $\mathrm{AgNO}_{3}$-impregnated silica gel and glass beads. During experiment, flow was switched after 30-90 min from one packed bed to the next, in order to avoid saturation. After experiment, a $\mathrm{NH}_{4} \mathrm{OH}$ solution was used to liberate the trans-compound. With this optimized method using microreactors, 85\% conversion can be achieved for trans-for-cis isomerization of cyclooctenol in $3 \mathrm{~h}\left(\mathrm{ESI}^{\dagger}\right)$, compared to a reported $73 \%$ in $8 \mathrm{~h}$ or $70 \%$ 
<smiles>O[C@@H]1CCC=CCCC1</smiles><smiles>CC(C)(O)COC1(C)CCC=CCCCC1</smiles>

6<smiles>[R]C(C)(C)COC1(C)CCC=CCCC1</smiles>

6: $\mathrm{R}^{2}=\mathrm{OH}$

8: $R^{2}=O M s$

9: $R^{2}=F$<smiles>COCC(C)(C)OCCC(C)(C)O[Pb]</smiles><smiles>[B-][OH+]C(C)(C)COC1(C)CCC=CCCC1</smiles>

5

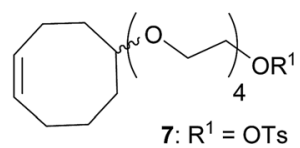
8: $R^{1}=$ OMs

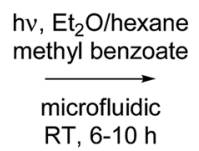

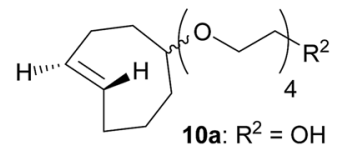

10a: $R^{2}=O H$
11a: $R^{2}=O M s$

2a: $R^{2}=F$
$96 \%$ $94 \%$

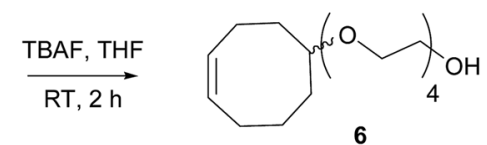

$64 \%$

6

$89 \%$

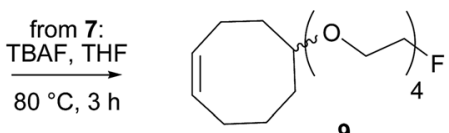

9

$96 \%$

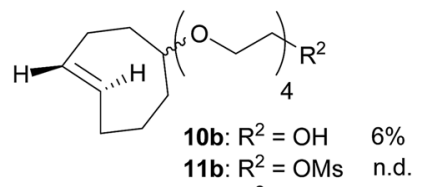<smiles>O[C@H]1CCC=CCC[C@H]1O</smiles>

12
$\prod_{\mathrm{O}}^{13} \mathrm{H}_{3}^{\mathrm{OBz}}$

p-toluenesulfonic acid THF, $50^{\circ} \mathrm{C}, 24 \mathrm{~h}$<smiles>CC(C)(C)OCCOC(C)(C)C1OC2CC/C=C\CCC2O1</smiles>

$60 \%$

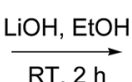<smiles>CC(C)(O)CCOC(C)(C)C1OC2CC/C=C\CCC2O1</smiles><smiles>CC(C)(O)CCOC(C)(C)C1OC2CC/C=C\CCC2O1</smiles>

15

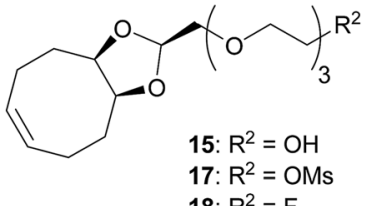

17: $R^{2}=$ OMs

18: $R^{2}=F$

\section{TsCl or $\mathrm{MsCl}, \mathrm{NEt}_{3}$ DMAP, $\mathrm{CH}_{2} \mathrm{Cl}_{2}$ $\overrightarrow{\mathrm{RT}, 1-3 \mathrm{~h}}$}

$\mathrm{hv}, \mathrm{Et}_{2} \mathrm{O} /$ hexane or TBME methyl benzoate $\overrightarrow{\text { microfluidic }}$ microfluidic
$\mathrm{RT}, 6-10 \mathrm{~h}$

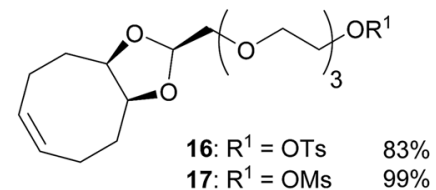

16: $R^{1}=O T s$ $83 \%$

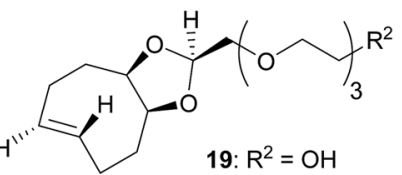

9: $R^{2}=\mathrm{OH} \quad 21 \%$ 20: $R^{2}=$ OMs $\quad 44 \%$ 3: $R^{2}=F$

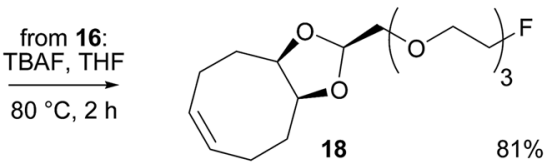

THF tetrahydrofuran, MsCl mesyl chloride, TsCl tosyl chloride, DMAP 4-(dimethylamino)pyridine, TBME tert-butyl methyl ether, n.d. not determined

Scheme 1 Syntheses of dienophiles $2 \mathrm{a}, 2 \mathrm{~b}$ and 3.

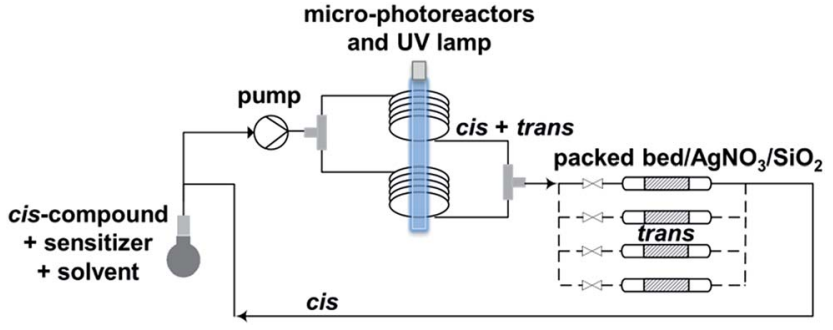

Scheme 2 Microfluidic setup optimized for trans-for-cis isomerization of functionalized cyclooctene derivatives.

in $3 \mathrm{~h}$ for non-microfluidic productions. ${ }^{13,16}$ For the new functionalized cyclooctene derivatives, photoisomerization yields reached $76 \%$ for a $6 \mathrm{~h}$ experiment, with fluoro-compound 3. For sulfonate precursors, only mesylate $\mathbf{1 1 b}$ and $\mathbf{2 0}$ could be isolated after isomerization, but 11b was quite unstable (data not shown).

\section{Reactivity and stability of new dienophiles}

Rate constants for reaction between new dienophiles and 3,6-di(pyridin-2-yl)-1,2,4,5-tetrazine in $\mathrm{MeOH}$ at $25{ }^{\circ} \mathrm{C}$ were determined by UV-spectrophotometry at $290 \mathrm{~nm}$ under pseudofirst order conditions (Fig. $\mathrm{S} 2 \dagger$ ). Compounds $10 \mathrm{a}$ and $10 \mathrm{~b}$ react with the tetrazine with rate constants of $476 \pm 33 \mathrm{M}^{-1} \mathrm{~s}^{-1}$ and $1913 \pm 196 \mathrm{M}^{-1} \mathrm{~S}^{-1}$ respectively. Compared to trans-cyclooctenol rate constants $\left(392 \pm 6 \mathrm{M}^{-1} \mathrm{~s}^{-1}\right.$ for major isomer and $300 \pm$ $22 \mathrm{M}^{-1} \mathrm{~s}^{-1}$ for minor isomer), the presence of the PEG chain on 10a and 10b does not reduce the reactivity. Reaction rate of 19 with the tetrazine is also fast, with a rate constant of $1620 \pm$ $149 \mathrm{M}^{-1} \mathrm{~s}^{-1}$. These rate constants are comparable to the ones 


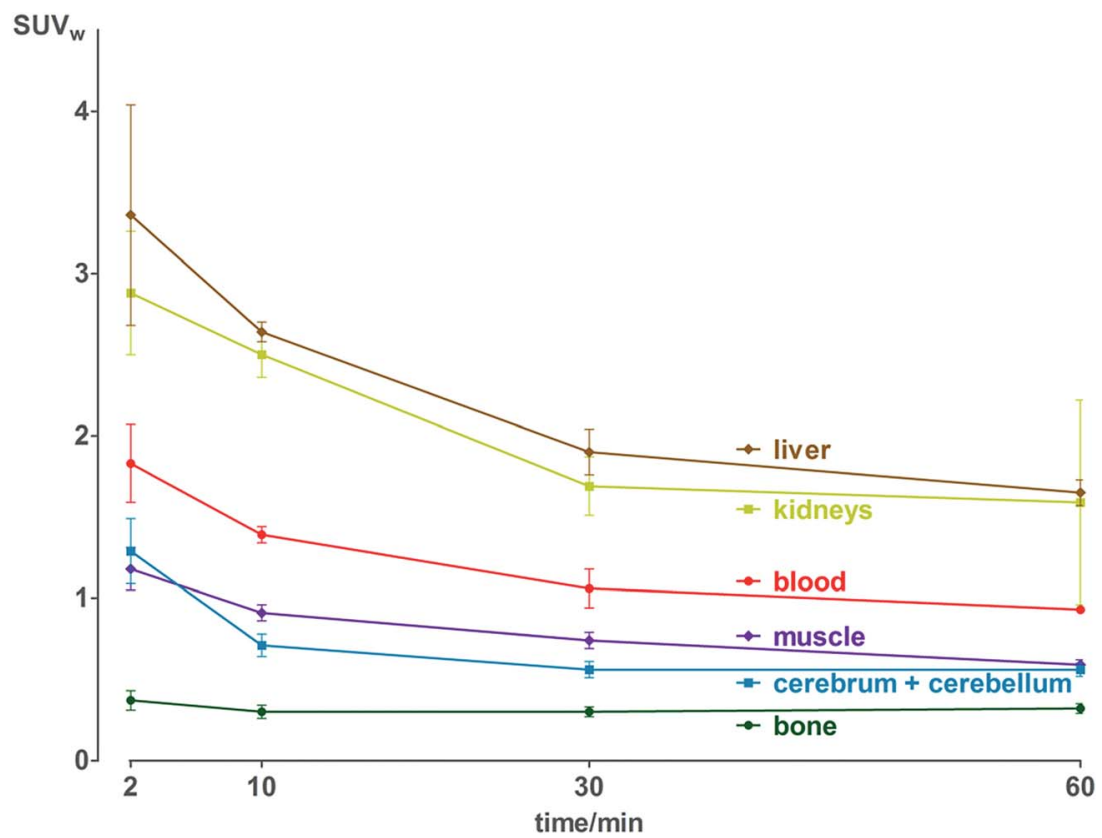

Fig. 2 Biodistribution of radioactivity after injection of $\left[{ }^{18} \mathrm{~F}\right] 3$ in healthy NMRI mice in selected organs and fluids. Data are expressed as standardized uptake value $\left(S_{U} \cup V_{w}\right)$.<smiles>O=C(O)CC[C@H](NC(=O)NC(CCCCNC(=O)CCCC(=O)Nc1cccc(-c2nnc(-c3ccc(C(F)(F)F)cc3)nn2)c1)C(=O)O)C(=O)O</smiles>

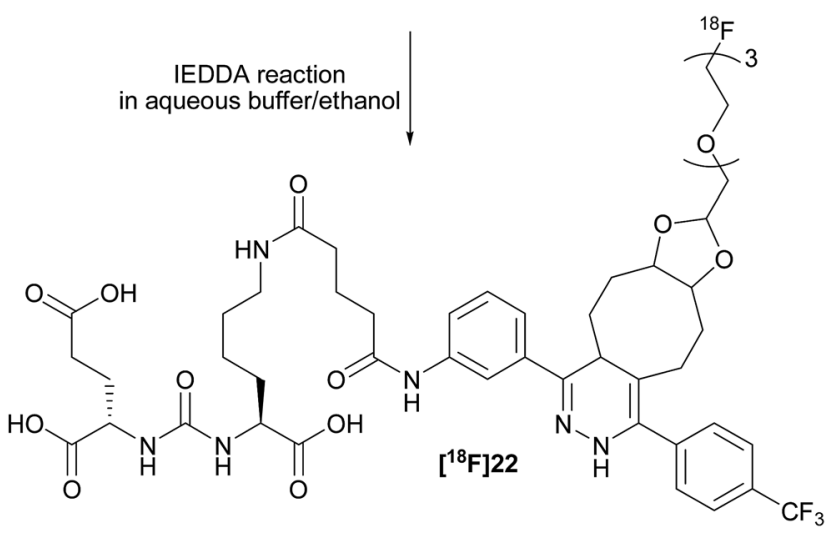

Scheme 3 Reaction between dienophile $\left[{ }^{18} \mathrm{~F}\right] 3$ and tetrazine 21 leads to $\left[{ }^{18} \mathrm{~F}\right] 22$ (mixture of isomers) quantitatively in a few seconds. reported in literature for this type of dienophiles. ${ }^{6 a, 12}$ While the new dienophiles are reactive toward a tetrazine, they also display excellent stability. Indeed, fluoro-trans-derivatives $\mathbf{2 a}, \mathbf{2 b}$ and $\mathbf{3}$ are stable in phosphate-buffered saline (PBS, pH 7.4) at $37^{\circ} \mathrm{C}$ for $19 \mathrm{~h}$ at least, as determined by HPLC (Tables S3, S5 and S7 $\dagger$ ).

\section{Radiolabeling with fluorine-18}

In view of the limited stability of precursors for radiofluorination 11a and 11b, we decided to continue the project with dioxolane-fused trans-cyclooctene compounds only. Semiautomated radiosynthesis of $\left[{ }^{18} \mathbf{F}\right] \mathbf{3}$ was performed on a homemade module. Nucleophilic substitution on mesylate precursor 20 by reaction with dry $\mathrm{K}\left[{ }^{18} \mathrm{~F}\right] \mathrm{F}, \mathrm{K}_{222}$ complex was achieved in $\mathrm{MeCN}$ at $90{ }^{\circ} \mathrm{C}$ for $15 \mathrm{~min}$. During radiosynthesis of $\left[{ }^{18} \mathbf{F}\right] \mathbf{3}$, less than $1 \%$ of cis-compound $\left[{ }^{18} \mathbf{F}\right] \mathbf{1 8}$ was generated. After purification by HPLC, $\left[{ }^{18} \mathbf{F}\right] 3$ was obtained in $60 \mathrm{~min}$, with $12 \%$ radiochemical yield (decay-corrected), a radiochemical purity $>99 \%$ (Fig. S4†), and a specific activity of $70-188 \mathrm{GBq} \mu \mathrm{mol}^{-1}$.

\section{In vitro stability of $\left[{ }^{18 / 19} \mathrm{~F}\right] 3$}

In PBS (pH 7.4), $\left[{ }^{18} \mathbf{F}\right] 3$ was rather stable, with $94 \%$ of intact compound after $2 \mathrm{~h}$ incubation at $37^{\circ} \mathrm{C}$. In rat plasma, $\left[{ }^{18} \mathrm{~F}\right] 3$ slowly isomerized into the corresponding cis-derivative $\left[{ }^{18} \mathbf{F}\right] \mathbf{1 8}$, with $52 \%$ and $34 \%$ of intact trans-compound after $1 \mathrm{~h}$ and $2 \mathrm{~h}$ incubation at $37^{\circ} \mathrm{C}$ respectively (Fig. S5 $\dagger$ ). For pretargeted PET imaging, this slow degradation is not an issue, as the IEDDA reaction takes place in a few seconds and plasma clearance is expected to be relatively fast ( $<30 \mathrm{~min})$. Additional experiments were performed to investigate the cause(s) of the isomerization, ${ }^{7 b, 12}$ and the presence of a thiol (2-mercaptoethanol) or 


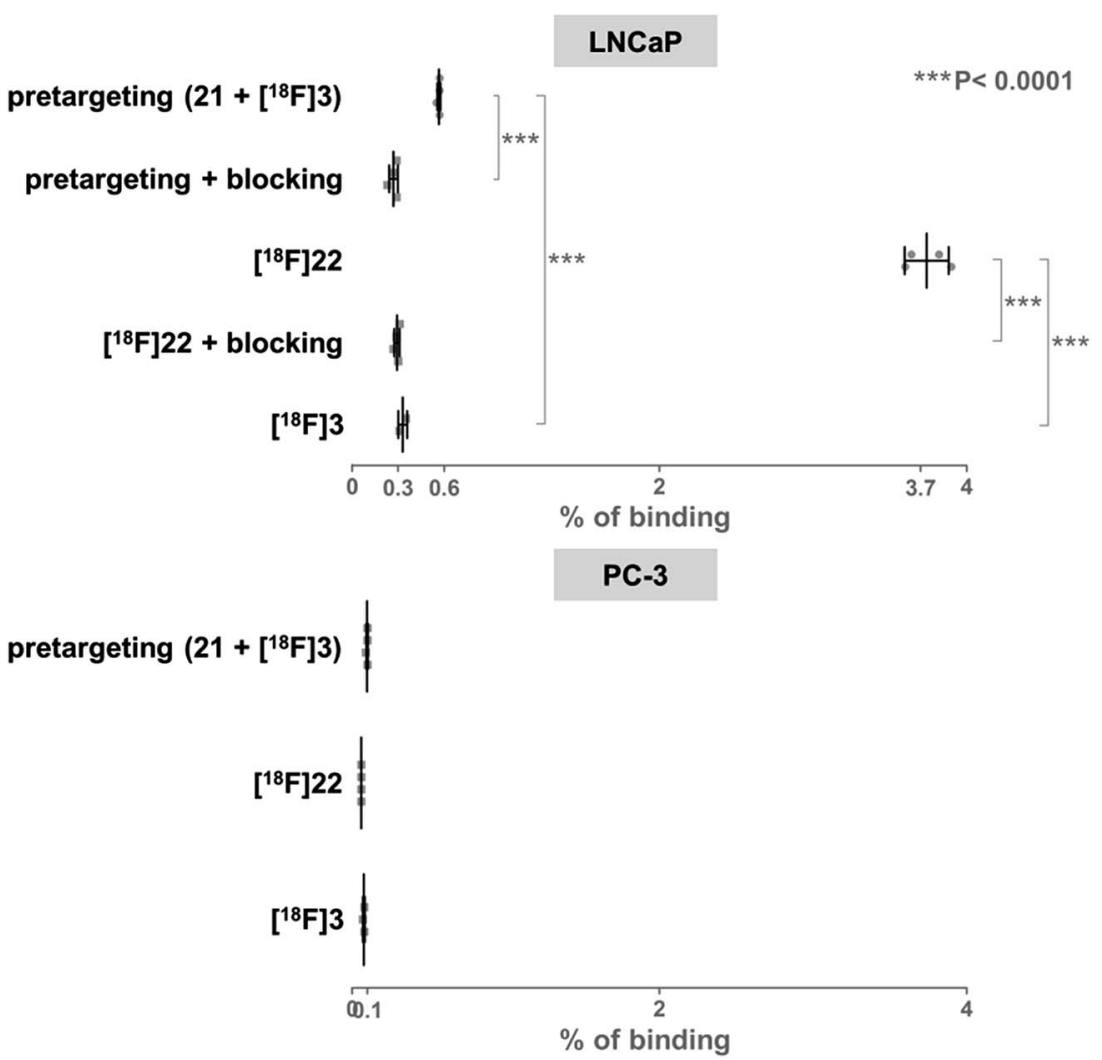

Fig. 3 Percentage of binding of radioactivity to LNCaP tumor slices after a pretargeting experiment with successive addition of 21 and [ $\left.{ }^{18} \mathrm{~F}\right] 3$ or after incubation with $\left[{ }^{18} \mathrm{~F}\right] 22$ was significantly higher than in control experiments.

temperature were found to promote cis-for-trans isomerization of 3 (Table S8 and Fig. S3†).

Biodistribution of radioactivity after injection of $\left[{ }^{18} \mathbf{F}\right] 3$

Pharmacokinetic profile of $\left[{ }^{\mathbf{1 8}} \mathbf{F}\right] \mathbf{3}$ was evaluated in vivo, in healthy NMRI mice, from 2 to 60 min p.i. (Fig. 2 and Table S11 $\dagger$ ). Results demonstrate absence of in vivo defluorination, as no significant bone uptake was observed at $60 \mathrm{~min}$ p.i. $(0.3 \pm$ $0.0 \mathrm{SUV}_{\mathrm{w}}$ ). Radioactivity was cleared via urinary and hepatobiliary systems. Interestingly, brain uptake was observed $(1.3 \pm 0.2$ to 0.6 $\pm 0.0 \mathrm{SUV}_{\mathrm{w}}$ from 2 to $60 \mathrm{~min}$ p.i.). Analysis of brain and biofluids by HPLC after 15 min p.i. revealed $20.8 \pm 1.1 \%$ of intact $\left[{ }^{18} \mathbf{F}\right] 3$ in brain, $5.9 \pm 0.6 \%$ in plasma and $0.1 \pm 0.0 \%$ in urine (Fig. S6 $\dagger$ ), indicating fast metabolism.

\section{In vitro pretargeting experiments using $\left[{ }^{18} \mathrm{~F}\right] 3$}

To check the usefulness of $\left[{ }^{18} \mathbf{F}\right] \mathbf{3}$ as a new dienophile for IEDDA reactions and for pretargeted PET imaging, in vitro and in vivo experiments were performed using a pseudo peptide with affinity for prostate-specific membrane antigen (PSMA) ${ }^{17}$ conjugated to 3-(4-(trifluoromethyl)phenyl)-6-phenyl-1,2,4,5tetrazine $^{\mathbf{1 0 f}}$ (21, Scheme 3, synthesis described in ESI $\left.\dagger\right)$.

For in vitro experiments, prostate tumor slices (LNCaP and PC-3 cells) were incubated with 21 , washed, and $\left[{ }^{18} \mathbf{F}\right] 3$ was added. Direct incubation with "preclicked"-compound $\left[{ }^{18} \mathbf{F}\right] 22$
(Scheme 3, Fig. S7 $\dagger$ ) was also performed. To check the specificity of the approach, blocking experiments with the non-structural related inhibitor 2-(phosphonomethyl)pentane-1,5-dioic acid ${ }^{18}$ and incubation with $\left[{ }^{18} \mathbf{F}\right] \mathbf{3}$ only were also carried out. The fraction of bound activity was determined after autoradiography (Fig. 3 and S9†). Significant PSMA-specific binding to LNCaP tumor slices (expressing PSMA receptors) was observed in the pretargeting experiment, but it was lower than the specific binding of "preclicked"-compound $\left[{ }^{\mathbf{1 8}} \mathbf{F}\right] \mathbf{2 2}$. In PC-3 cells (negative control), no significant binding was observed.

\section{Proof of principle in vivo PET imaging}

On the basis of these promising results, proof of principle PET imaging experiments were conducted in LNCaP prostate tumorbearing mice. Compound $21(50 \mu \mathrm{g})$ was administered intratumorally $10 \mathrm{~min}$ before intravenous (i.v.) injection of $\left[{ }^{18} \mathbf{F}\right] \mathbf{3}$, following a similar protocol reported by Emmetiere et al. ${ }^{7 f}$ to avoid variability due to tetrazine concentration in target tissues. Dynamic (0-60 min p.i.) and static (120 min p.i.) microPET scans were acquired. PET imaging with $\left[{ }^{18} \mathbf{F}\right] 3$ allowed visualization of the tumor, as shown in Fig. 4. Moreover, tumor uptake was significantly higher than muscle uptake, as early as $30 \mathrm{~min}$ p.i. and up to $2 \mathrm{~h}$ p.i. In order to ensure that the tumor accumulation was due to the ${ }^{18} \mathrm{~F}$-labeled conjugate formed by the IEDDA reaction, control experiments were also performed in mice that received only i.v. injection of $\left[{ }^{18} \mathbf{F}\right] \mathbf{3}$. Uptake of radioactivity in the 

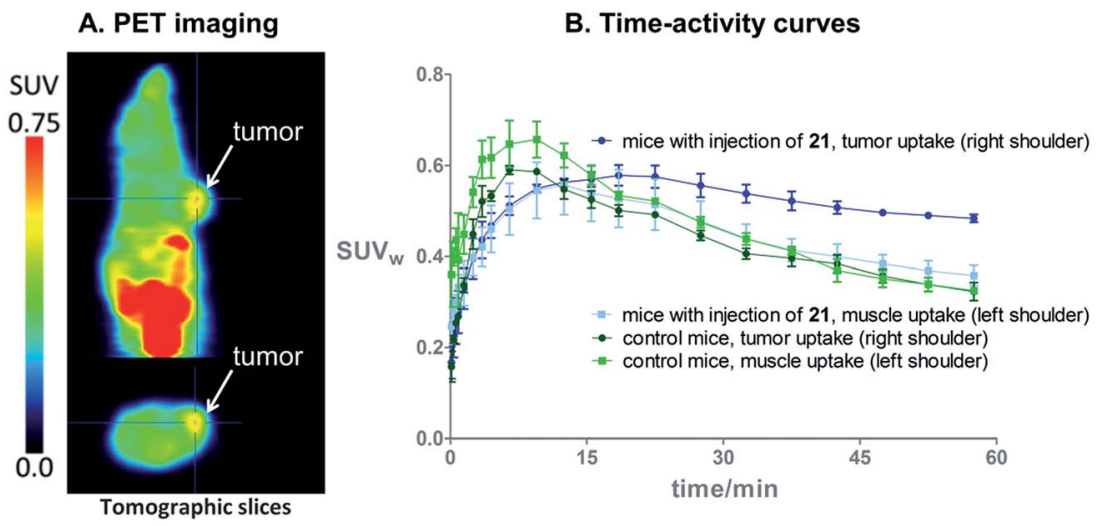

Fig. 4 (A) In vivo PET images $2 \mathrm{~h}$ after i.v. injection of bioorthogonal $\left[{ }^{18} \mathrm{~F}\right] 3(11 \mathrm{MBq})$, in a mouse bearing an LNCaP tumor treated with tetrazine 21 $(50 \mu \mathrm{g})$. (B) Time-activity curves from 0 to $60 \mathrm{~min}$ after i.v. injection of $\left[{ }^{18} \mathrm{~F}\right] 3$, in LNCaP tumor-bearing mice with $(N=3)$ or without $(=\mathrm{control}, N=$ 3) intratumoral injection of 21.

A. PET imaging

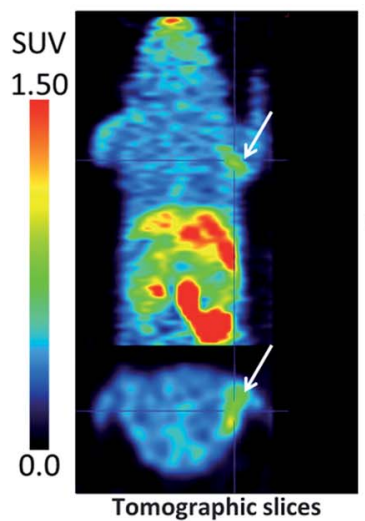

\section{B. Time-activity curves}

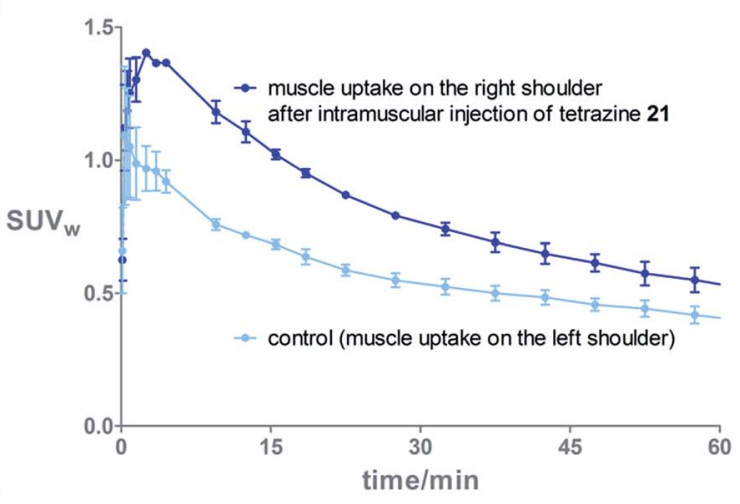

Fig. 5 (A) In vivo PET images 60 min after i.v. injection of $\left[{ }^{18} \mathrm{~F}\right] 3$ (11 MBq) in an healthy NMRI mouse which received an intramuscular injection of tetrazine $21(50 \mu \mathrm{g})$ in the muscle on the right shoulder (arrows), and saline with 10\% dimethyl sulfoxide in the muscle on the left shoulder. (B) Time-activity curves from 0 to 60 min after i.v. injection of $\left[{ }^{18} \mathrm{~F}\right] 3$, in healthy NMRI mice $(N=3)$. The uptake of radioactivity in the tetrazineenriched tissue is significantly higher than in the tissue which received only the vehicle, from 3 min to $47 \mathrm{~min}$ p.i. of $\left[{ }^{18} \mathrm{~F}\right] 3$

tumor was significantly lower than in tetrazine-21-preinjected tumors, from $30 \mathrm{~min}$ to $2 \mathrm{~h}$ p.i. (Fig. 4 and S10†). No significant difference was observed between muscle uptake and tumor uptake in control experiments. According to another PET imaging experiment (Fig. 5 and S11 $\dagger$ ), the accumulation of radioactivity in tetrazine-enriched tissues is not an effect due to the injection of the tetrazine, as the injection of the same volume of vehicle alone (saline with $10 \%$ dimethyl sulfoxide) does not lead to a significant uptake of radioactivity.

These proof of principle experiments demonstrate the usefulness of $\left[{ }^{18} \mathbf{F}\right] \mathbf{3}$ for the in vivo IEDDA reaction. In order to successfully apply this new dienophile to pretargeted immunoPET, stability will be favored over reactivity for the choice of the tetrazine, as a tetrazine-derivatised antibody will be injected several days before the radiolabeled dienophile. A tetrazine such as reported by Selvaraj et al., ${ }^{10 f}$ or by Karver et al. ${ }^{7 c}$ possibly modified with a PEG linker, might be a good choice.

\section{Conclusions}

In summary, we developed three new dienophiles for IEDDA reactions, and compound 3 was selected for pretargeting applications. trans-3 has been prepared via diastereoselective synthesis, and the trans-for-cis isomerization step has been performed by micro-flow photochemistry with $76 \%$ yield. The new microfluidic setup reported here can be applied as continuous process which is promising for process scale-up. ${ }^{18} \mathrm{~F}$-radiolabeling of 3 can be carried out by nucleophilic substitution at high specific activity, in $60 \mathrm{~min}$, with $12 \%$ radiochemical yield, and $>99 \%$ radiochemical purity. In vivo, $\left[{ }^{18} \mathbf{F}\right] 3$ demonstrated a suitable pharmacokinetic profile and no defluorination was observed. Proof of principle PET imaging experiments with $\left[{ }^{18} \mathbf{F}\right] \mathbf{3}$, on a prostate tumor model injected with a tetrazine-coupled PSMA antagonist $10 \mathrm{~min}$ before radiotracer injection, allowed clear visualization of the tumor tissue, due to the ${ }^{18} \mathrm{~F}$-labeled conjugate formed by the IEDDA 
reaction. In conclusion, new dienophile $\left[{ }^{18} \mathbf{F}\right] \mathbf{3}$ seems suitable for pretargeted PET imaging, although further structural modification can still be done to favor urinary excretion. In the future, $\left[{ }^{18} \mathbf{F}\right] \mathbf{3}$ will be investigated for pretargeted immunoPET, by using a tetrazine-derivatised antibody.

\section{Acknowledgements}

The authors thank Julie Cornelis, Pieter Haspeslagh, Ivan Sannen, Michiel Nuyts, Jana Hemelaers from the Laboratory of Radiopharmacy, and Ann Van Santvoort, Tinne Buelens from Nuclear Medicine and Molecular Imaging, for their assistance. This research project received support from IWT Flanders (SBO 130065 MIRIAD) and the European Research Council (Advanced Grant "Novel Process Windows - Boosted Micro Process Technology" 267443).

\section{References}

1 E. D. G. Fleuren, Y. M. H. Versleijen-Jonkers, S. Heskamp, C. M. L. van Herpen, W. J. G. Oyen, W. T. A. van der Graaf and O. C. Boerman, Mol. Oncol., 2014, 8, 799.

2 L. E. Lamberts, S. P. Williams, A. G. T. Terwisscha van Scheltinga, M. N. Lub-de Hooge, C. P. Schröder, J. A. Gietema, A. H. Brouwers and E. G. E. de Vries, J. Clin. Oncol., 2015, 33, 1491.

3 M. A. Deri, B. M. Zeglis, L. C. Francesconi and J. S. Lewis, Nucl. Med. Biol., 2013, 40, 3.

4 K. Serdons, A. Verbruggen and G. M. Bormans, Methods, 2009, 48, 104.

5 D. A. Goodwin, C. F. Meares, M. J. McCall, M. McTigue and W. Chaovapong, J. Nucl. Med., 1988, 29, 226.

6 (a) M. L. Blackman, M. Royzen and J. M. Fox, J. Am. Chem. Soc., 2008, 130, 13518; (b) T. Reiner and B. M. Zeglis, J. Labelled Compd. Radiopharm., 2014, 57, 285.

7 (a) N. K. Devaraj, R. Upadhyay, J. B. Haun, S. A. Hilderbrand and R. Weissleder, Angew. Chem., Int. Ed., 2009, 48, 7013; (b) R. Rossin, P. Renart Verkerk, S. M. van den Bosch, R. C. M. Vulders, I. Verel, J. Lub and M. S. Robillard, Angew. Chem., Int. Ed., 2010, 49, 3375; (c) M. R. Karver, R. Weissleder and S. A. Hilderbrand, Bioconjugate Chem., 2011, 22, 2263; (d) G. Budin, H. Jung Chung, H. Lee and R. Weissleder, Angew. Chem., Int. Ed., 2012, 51, 7752; (e) R. Rossin, S. M. van den Bosch, W. ten Hoeve, M. Carvelli, R. M. Versteegen, J. Lub and M. S. Robillard, Bioconjugate Chem., 2013, 24, 1210; (f) F. Emmetiere, C. Irwin, N. T. Viola-Villegas, V. Longo, S. M. Cheal, P. Zanzonico, N. Pillarsetty, W. A. Weber, J. S. Lewis and T. Reiner, Bioconjugate Chem., 2013, 24, 1784; $(g)$ B. M. Zeglis, K. K. Sevak, T. Reiner, P. Mohindra, S. D. Carlin, P. Zanzonico, R. Weissleder and J. S. Lewis, J. Nucl. Med., 2013, 54, 1389; $(h)$ R. Rossin, T. Läppchen, S. M. van den Bosch, R. Laforest and M. S. Robillard, J. Nucl. Med., 2013, 54, 1989; ( $i$ ) H. L. Evans, Q.-D. Nguyen, L. S. Carroll, M. Kaliszczak, F. J. Twyman, A. C. Spivey and E. O. Aboagye, Chem. Commun., 2014, 50, 9557; (j) R. Rossin, S. M. J. van Duijnhoven, T. Läppchen, S. M. van den Bosch and M. S. Robillard, Mol. Pharmaceutics, 2014, 11, 3090; (k) S. M. J. van Duijnhoven, R. Rossin, S. M. van den Bosch, M. P. Wheatcroft, P. J. Hudson and M. S. Robillard, J. Nucl. Med., 2015, 56, 1422; (l) B. M. Zeglis, C. Brand, D. Abdel-Atti, K. E. Carnazza, B. E. Cook, S. Carlin, T. Reiner and J. S. Lewis, Mol. Pharmaceutics, 2015, 12, 3575; $(m)$ J. L. Houghton, B. M. Zeglis, D. Abdel-Atti, R. Sawada, W. W. Scholz and J. S. Lewis, J. Nucl. Med., 2016, 57, 453; (n) M. Altai, A. Perols, M. Tsourma, B. Mitran, H. Honarvar, M. Robillard, R. Rossin, W. ten Hoeve, M. Lubberink, A. Orlova, A. Eriksson Karlström and V. Tolmachev, J. Nucl. Med., 2016, 57, 431; (o) N. K. Devaraj, R. Weissleder and S. A. Hilderbrand, Bioconjugate Chem., 2008, 19, 2297; (p) B. Nichols, Z. Qin, J. Yang, D. R. Vera and N. K. Devaraj, Chem. Commun., 2014, 50, 5215.

8 (a) N. K. Devaraj, G. M. Thurber, E. J. Keliher, B. Marinelli and R. Weissleder, Proc. Natl. Acad. Sci. U. S. A., 2012, 109, 4762; (b) C. Denk, D. Svatunek, T. Filip, T. Wanek, D. Lumpi, J. Fröhlich, C. Kuntner and H. Mikula, Angew. Chem., Int. Ed., 2014, 53, 9655; (c) J.-P. Meyer, J. L. Houghton, P. Kozlowski, D. Abdel-Atti, T. Reiner, N. V. K. Pillarsetty, W. W. Scholz, B. M. Zeglis and J. S. Lewis, Bioconjugate Chem., 2016, 27, 298.

9 (a) Z. Li, H. Cai, M. Hassink, M. L. Blackman, R. C. D. Brown, P. S. Conti and J. M. Fox, Chem. Commun., 2010, 46, 8043; (b) L. Wyffels, D. Thomae, A.-M. Waldron, J. Fissers, S. Dedeurwaerdere, P. Van der Veken, J. Joossens, S. Stroobants, K. Augustyns and S. Staelens, Nucl. Med. Biol., 2014, 41, 513.

10 (a) T. Reiner, E. J. Keliher, S. Earley, B. Marinelli and R. Weissleder, Angew. Chem., Int. Ed., 2011, 50, 1922; (b) R. Selvaraj, S. Liu, M. Hassink, C.-W. Huang, L.-P. Yap, R. Park, J. M. Fox, Z. Li and P. S. Conti, Bioorg. Med. Chem. Lett., 2011, 21, 5011; (c) E. J. Keliher, T. Reiner, G. M. Thurber, R. Upadhyay and R. Weissleder, ChemistryOpen, 2012, 1, 177; (d) Z. Wu, S. Liu, M. Hassink, I. Nair, R. Park, L. Li, I. Todorov, J. M. Fox, Z. Li, J. E. Shively, P. S. Conti and F. Kandeel, J. Nucl. Med., 2013, 54, 244; (e) S. Liua, M. Hassink, R. Selvaraj, L.-P. Yap, R. Park, H. Wang, X. Chen, J. M. Fox, Z. Li and P. S. Conti, Mol. Imaging, 2013, 12, 121; $(f)$ R. Selvaraj, B. Giglio, S. Liu, H. Wang, M. Wang, H. Yuan, S. R. Chintala, L.-P. Yap, P. S. Conti, J. M. Fox and Z. Li, Bioconjugate Chem., 2015, 26, 435.

11 (a) G. Molineux, Cancer Treat. Rev., 2002, 28(A), 13; (b) J. M. Harris and R. B. Chess, Nat. Rev. Drug Discovery, 2003, 2, 214; (c) F. M. Veronese and G. Pasut, Drug Discovery Today, 2005, 10, 1451.

12 A. Darko, S. Wallace, O. Dmitrenko, M. M. Machovinac, R. A. Mehl, J. W. Chin and J. M. Fox, Chem. Sci., 2014, 5, 3770.

13 M. Royzen, G. P. A. Yap and J. M. Fox, J. Am. Chem. Soc., 2008, 130, 3760 .

14 (a) D. Cambie, C. Bottecchia, N. J. W. Straathof, V. Hessel and T. Noël, Chem. Rev., 2016, 116, 10276; (b) Y. Su, N. J. W. Straathof, V. Hessel and T. Noël, Chem.-Eur. J., 2014, 20, 10562. 
15 Y. Su, K. Kuijpers, V. Hessel and T. Noël, React. Chem. Eng., 2016, 1, 73.

16 D. Svatunek, C. Denk, V. Rosecker, B. Sohr, C. Hametner, G. Allmaier, J. Fröhlich and H. Mikula, Monatsh. Chem., 2016, 147, 579.
17 M. Eder, M. Schäfer, U. Bauder-Wüst, W.-E. Hull, C. Wängler, W. Mier, U. Haberkorn and M. Eisenhut, Bioconjugate Chem., 2012, 23, 688.

18 P. F. Jackson, D. C. Cole, B. S. Slusher, S. L. Stetz, L. E. Ross, B. A. Donzanti and D. A. Trainor, J. Med. Chem., 1996, 39, 619. 